\title{
ZOOS' PRINT JOURNAL, A SHORT HISTORY AND THE WAY FORWARD
}

This is the first issue of the sixth year of Zoos' Print Journal! This issue is different from the preceding 60 issues: it contains an Editorial, a more professional layout, and a web-based edition with colour photos. It is fitting now to relate some publication statistics as well as the learning curve this journal has undergone.

In the nearly six years since I was given the responsibility of being the editor of Zoos' Print, I have learned that keeping up a monthly journal is not so easy. In all these years, my respect for the previous editor's contribution has not waned; instead Sally Walker's motivation has kept this monthly still a monthly. Into its $19^{\text {th }}$ year of publication, Zoos' Print certainly has come a long way — from being a zoo magazine and a source of new information at a continuous clip for both wildlife and animal welfare contributors as well as zoo personnel and a newsletter for all the different network activities of the organisation, and from being the only consistently published zoo and wildlife magazine in Asia ... to having a successful peer-reviewed journal inside its pages. The changes have not happened in a hurry but have evolved in line with the wishes and suggestions of our growing number of readers. Zoos' Print always received some scientific articles, which were published first with only editorial changes and later after checking facts. We realised and were reminded by well-wishers that many of these scientific articles were potentially of journal quality and should be reviewed as such. We debated this for some time but when we started receiving taxonomic articles with new descriptions, our mandate was clear.

ZPJ started in April 1999 with just 12 pages and even we were surprised to get a continuous supply of articles thereafter. The experiment was worth the risk! Although the journal is much appreciated it is still misunderstood. Just as Zoos' Print magazine was (and probably is) criticized for its lack of sophistication, some concerned persons say that the journal lacks scientific 'edge'. $Z P J$ was established with the objective of providing an opportunity for academically inclined wildlifers to publish their work in a timely manner, not to be so scientifically exclusive that only polished and experienced writers qualify. $Z P J$ provides a way for students, budding scientists and academics whose first language is not English to publish. India and other South Asian countries are infamous for the lack of publications in wildlife or conservation. In our bid to encourage people we focus on the scientific merit and other positive aspects of the work rather than language or presentation style. Scientific validity is questionable to an extent in any journal, but some Indian and regional scientists and biologists who did not stand a chance of publication in an international journal due to their limitations in presentation, style or language have been encouraged in ZPJ. And, just as has happened with the magazine, as our contributors have improved, we will also !

Among peer-reviewed journals, the credibility of $Z P J$ increases with its listings. $Z P J$ is indexed and abstracted by at least seven agencies both within the country and abroad. The journal was evaluated for one year in some cases before being indexed or abstracted, an achievement we credit to our contributors. Apart from a very few specialized journals in this region, many well established wildlife or conservation publications do not find an impact factor rating, an imbalance suffered by regional publications all over the world due to undue influence on impact factor by developed regions' scientists. (This is another reason why South Asian scientists should publish more!)

$Z P J$ article composition is interesting. In 60 issues and 1422 pages of print, a total of 456 articles include 262 on wildlife ( 22 catalogues, 21 new records, 142 field reports, 56 notes and 21 reviews), 64 on taxonomy, 27 on zoo, botanical garden and laboratory studies, 102 on veterinary aspects and one book review. More specifically, $Z P J$ has also attracted some articles on plants and in the last two years a series of new descriptions of fungi. $Z P J$ has been a boon for invertebrate researchers as 116 articles on invertebrates have appeared out of which 25 have been on new descriptions. New sections have been started to give focus to the publications, such as Fauna of protected areas.

Our effort has continuously been to improve the standard of publications and that of the journal. The veterinary section is one of the more popular ones, which have been reduced from Case Reports in earlier issues to Vet Briefs in the more recent issues. This 'improvement' was mainly in keeping with encouraging the contributors to come up with a better style of presentation. A more complete and well laid out presentation with more research could make Papers or Case Reports of veterinary articles.

We are celebrating the completion of five years of publication by introducing with this issue a web-based edition of the journal, which can be downloaded at www.zoosprint.org as pdf format. An additional feature is that the printed articles will be supplemented by more information on the web, indicated appropriately on the printed version as well as the web version. In this issue, we have four articles for which photographs that cannot be published in the printed version are put up on the web for reference. We intend to make the web supplements an integral part of the publication, which would also be reflected in the citation. For example, the plant article by R. Vijaya Sankar, et al., which has a web supplement would be cited as:

Vijaya Sankar, R., K. Ravikumar and P. Ravichandran (2004). Dipteracanthus beddomei (C.B. Clarke) Santapau (Acanthaceae): A new report to southern India. Zoos' Print Journal 19(4): 1442 i where $\mathbf{1 4 4 2}$ is the printed page/s and $\sim \mathbf{i}$ indicates the web supplement page/s for the article.

The impetus for this expansion of the format of $Z P J$ was motivated also by a grant from the Chester Zoo / North of England Zoological Society for the purpose of sponsoring the journal.

We at Zoo Outreach Organisation welcome you to share your contributions and concerns with this monthly and help us to improve $Z P J$ in the months and years to come.

Sanjay Molur Editor

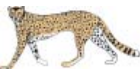

\section{Visit www.zoosprint.org for the online version of the journal and for supplements}

